\title{
Platelets and Neutrophils from Healthy Term Neonates Exhibit Increased Levels of Immunoglobulins
}

\author{
CHRISTOPHER C. SILLIMAN, NANCY A. CUSACK, NANCY J. SWANSON, \\ SIMIN GHAFFARIFAR, AND DANIEL R. AMBRUSO \\ Departments of Research and Special Immunology [C.C.S, N.A.C., N.J.S., S.G., D.R.A.], Bonfils Memorial \\ Blood Center and Department of Pediatrics [C.C.S., D.R.A.], University of Colorado School of Medicine, \\ Denver, Colorado 80262
}

\begin{abstract}
Immune-mediated thrombocytopenia and neutropenia are not uncommon problems in the newborn period. Such cytopenias have been associated with increased levels of $\operatorname{IgG}, \operatorname{IgM}$, or both, in the serum, documented by indirect assay, and/or on the cell surface, documented by direct assay, and decreased cell survival. However, interpretation of measurement of platelet- or neutrophil-associated antibodies is problematic due to the lack of data from healthy neonates. In this study, both direct and indirect neutrophil- and platelet-associated IgG and IgM were measured in cord samples from 44 healthy, term neonates. These infants had increased amounts of direct platelet-associated IgG and direct neutrophil-associated IgM and IgG compared with adult controls. Serum samples from these healthy newborns manifested a significantly decreased level of IgM binding to target platelets compared with serum from healthy adult controls. There
\end{abstract}

\section{ABSTRACT}

was not a significant difference in direct platelet-associated IgM, or indirect Ig to neutrophils or platelets. Complete blood counts drawn at $24 \mathrm{~h}$ of age were within normal limits in 34/35 infants studied. Moreover, there was not a statistical difference in platelet or neutrophil Ig studies between the newborns of multiparous and primigravida mothers. The physiologic consequences of the increased amounts of these Ig to the survival and function of platelets and neutrophils in neonates is unclear. However, these values must be considered for proper interpretation of platelet and neutrophil Ig measurements in newborns with cytopenias. (Pediatr Res 38: 993-997, 1995)

CBC, complete blood count

\section{Abbreviations}

PMN, polymorphonuclear leukocyte
Thrombocytopenia and neutropenia are not uncommon findings in neonates $(1,2)$. Immune-mediated thrombocytopenia and neutropenia represent a significant etiology for these cytopenias $(3,4)$. These immune-mediated cytopenias may be characterized as alloimmune or autoimmune and result from increased amounts of IgG bound to the cell surface (direct) and/or identified in the serum (indirect) resulting in increased cell turnover $(3,5,6)$.

The laboratory evaluation of immune-mediated cytopenias depends upon the detection and quantitation of Ig against platelets and neutrophils compared with healthy controls (2, 4-6). However, the paucity of normal values for healthy, term infants hampers the interpretation and limits the diagnostic

Received January 12, 1995; accepted June 23, 1995

Correspondence: Daniel R. Ambruso, M.D., Bonfils Memorial Blood Center, 4200 E. 9th Ave., Box B-128, Denver, CO 80262.

Supported in part by the General Clinical Research Centers Program (5 M01 RR00069), National Center for Research Resources, National Institutes of Health, The Margery Wilson Transfusion Medicine Research Fellowship, Bonfils Blood Center, The Bugher Physician Scientist Training Program, The Stacy Marie True Memorial Trust, and the Transfusion Medicine Academic Award, NHLBI, National Institutes of Health (K07-HL02036) utility of these quantitative measurements applied to the nursery population. To define the normal ranges of direct and indirect platelet and neutrophil Ig in cord blood samples from healthy, term infants, we quantitated $\operatorname{IgG}$ and $\operatorname{IgM}$ on the surface of neutrophils and platelets as well as IgG and IgM from serum binding to target platelets and neutrophils after the delivery of 44 neonates.

\section{METHODS}

Study population. Cord blood was drawn from the placentas of 44 healthy, term infants born by vaginal delivery or by elective cesarean section to healthy mothers at the University of Colorado Health Sciences Center. Informed consent was obtained from the parents in accordance with guidelines approved by the Combined Internal Review Board, University of Colorado School of Medicine, to have the parents complete a detailed questionnaire and to draw a complete blood count on the newborns at $24 \mathrm{~h}$ of life at the time of routine neonatal screening. As additional controls, samples from nine women in the third trimester of pregnancy were also evaluated for the presence of direct and indirect platelet Ig. 
Materials. All chemicals and reagents were purchased from Sigma Chemical Co. (St. Louis, MO) except where noted. Citric acid, cupric sulfate, sulfuric acid, and paraformaldehyde were obtained from Fisher Scientific (Fair Lawn, NJ). A horseradish peroxidase-conjugated and affinity-purified $\mathrm{F}(\mathrm{ab})_{2}$ fragment of goat anti-human $\mathrm{IgG}$ and anti-human IgM heavy chain as well as $\operatorname{IgG}$ and $\operatorname{IgM}$ standards were purchased from Accurate Chemical and Scientific Corporation (Westbury, NY). Gelatin was obtained from Difco Laboratories (Detroit, $\mathrm{MI}$ ), and Nunc Maxisorb microtiter plates were purchased from Curtin Matheson Scientific, Inc (Houston, TX).

Isolation of platelets and neutrophils. Citrated whole blood was collected from the placentas of healthy, term neonates within ten minutes after delivery and from healthy adult controls. Platelets were isolated by standard techniques and resuspended in at a concentration of $4 \times 10^{7}$ platelets $/ \mathrm{mL}$. Neutrophils were isolated as reported previously and resuspended at a concentration of $2.25 \times 10^{6}$ neutrophils/mL (7).

Platelet-associated Ig. Standards for $\operatorname{IgG}$ and $\operatorname{IgM}$ were prepared by adding $100 \mu \mathrm{L}$ of varying dilutions of purified IgG and $\operatorname{IgM}$ in buffer containing $15 \mathrm{mM} \mathrm{Na}_{2} \mathrm{CO}_{3}, 35 \mathrm{mM}$ $\mathrm{NaHCO}_{3}$, and $0.02 \% \mathrm{NaN}_{3}, \mathrm{pH} 9.6$, to triplicate wells of Nunc Maxisorb microtiter plates and incubated at room temperature for $60 \mathrm{~min}$. In preliminary experiments, radiolabeled $\left({ }^{131} \mathrm{I}\right) \mathrm{IgG}$ and $\operatorname{IgM}$ were used to determine the extent of binding of the standards to the microtiter wells. Results from these experiments were used subsequently to calibrate standard curves in routine assays. After the plates were washed once, $2 \times 10^{6}$ control and subject platelets $(50 \mu \mathrm{L})$ were added to separate wells along with $100 \mu \mathrm{L}$ of $8 \%$ glutaraldehyde, and the plates were centrifuged at $1565 \times g$ for $15 \mathrm{~min}$. All wells were washed three times in PBS with $0.05 \%$ Tween 20 (PBSTween) and blotted and $250 \mu \mathrm{L}$ of PBS-Tween with $0.2 \%$ gelatin (PTG) was added to all wells. The plates were incubated for $15 \mathrm{~min}$ at room temperature, the fluid decanted, the wells blotted, and $100 \mu \mathrm{L}$ of horseradish peroxidase conjugated anti-IgG and anti-IgM (1/20,000 dilution in PBS-Tween-gelatin) was added to the wells. The plates were incubated for $45 \mathrm{~min}$ at $37^{\circ} \mathrm{C}$, then washed three times with PBS-tween, and blotted. Substrate for the peroxidase (100 $\mu \mathrm{L}$ of $7.5 \mathrm{mM}$ o-phenylenediamine and $0.48 \% \mathrm{H}_{2} \mathrm{O}_{2}$ in $55 \mathrm{mM}$ sodium phosphate, $23 \mathrm{mM}$ sodium citrate, $\mathrm{pH} 4.8$ ) was added to each well, and the mixtures were incubated for $25 \mathrm{~min}$ at room temperature in a darkened room. To stop the reaction, $100 \mu \mathrm{L}$ of $0.2 \mathrm{M} \mathrm{H}_{2} \mathrm{SO}_{4}$ was added to each well and the plates were read at $490 \mathrm{~nm}$ of light in an ELISA reader purchased from Molecular Devices (Menlo Park, CA). Quantitation of IgM and IgG was completed by interpolation from a standard Ig curve. The data were expressed as nanograms of $\mathrm{IgG}$ or IgM per $\mu \mathrm{g}$ of total platelet protein, measured on a separate $50-\mu \mathrm{L}$ aliquot of platelets by a modified Lowry procedure on each patient or control sample (8). Control values for each plate were calculated as the mean of results from four healthy adults run concurrently with subject samples.

Serum bindable platelet Ig. Serum from healthy neonates or a pool of serum made with samples from healthy adults, determined to be in the normal range by previous indirect assay, was incubated for $45 \mathrm{~min}$ at $37^{\circ} \mathrm{C}$ with target platelets made from a pool of four healthy, type $\mathrm{O}$, adult blood donors. Platelets were isolated from platelet-rich plasma as noted above, washed five times in PBS-EGTA, and resuspended to $7.5 \times 10^{8} / \mathrm{mL}$. To one volume of cells, one-third volume of $8 \%$ paraformaldehyde was added, and the mixture was incubated at room temperature for $5 \mathrm{~min}$ and centrifuged at $1250 \times g$ for 15 min. The platelet samples were resuspended in PBS-EGTA, pooled in $200-\mathrm{mL}$ conical tubes, and centrifuged at $1250 \times \mathrm{g}$ for $15 \mathrm{~min}$. The pooled platelets were resuspended in PBSTween at a concentration of $7.5 \times 10^{8}$ cells $/ \mathrm{mL}$. To complete the serum bindable test, $2 \times 10^{6}$ pooled platelets were added to each well of a microtiter plate, and the plate was centrifuged as noted above. After three washes with PBS-EGTA, PTG solution was added to each well, and the plate was incubated at room temperature for $15 \mathrm{~min}$. After decanting and blotting the plates, $100 \mu \mathrm{L}$ of serum from patients or a pool of normal adult controls was added to target cells in neat or 1/20 dilution. Each dilution was assayed in triplicate. Standard curves for IgG and IgM were plated as noted in the platelet-associated assay. After incubation of $45 \mathrm{~min}$ at $37^{\circ} \mathrm{C}$, the remainder of the assay was completed as described above. Protein assays were not completed on target platelets, and quantitation was completed by interpolation from a standard curve for $\operatorname{IgG}$ and $\operatorname{IgM}$ with the results expressed as nanograms/well. Preliminary studies with ${ }^{131} \mathbf{I}$ labeled target platelets determined that, although there was plate to plate variability of target platelets bound to the wells, there was no variability between wells within the same plate. Thus, serum bindable assays for IgG and IgM were always completed with controls on the same plate.

Neutrophil-associated Ig. PMN $\left(2.25 \times 10^{5}\right)$ were added to the wells of a microtiter plate and fixed with $8 \%$ gluteraldehyde, and an ELISA was performed with affinity-purified goat anti-human $\operatorname{IgG}$ and $\operatorname{IgM~} F\left(\mathrm{ab}^{\prime}\right)_{2}$ fragments in the identical direct procedure to that described for platelets. Quantitation of IgG and IgM was completed by interpolation from a standard curve. Initial control studies were completed using neutrophils labeled with ${ }^{111}$ In and demonstrated that $\geq 90 \%$ of neutrophils added to the microtiter plates were fixed to the wells. Therefore, the results were based upon the amount of Ig per the number of neutrophils plated and the results were expressed as femtograms/PMN.

Serum bindable neutrophil Ig. Serum from healthy, term neonates and from pools of healthy adult controls was incubated with target PMN $\left(2.25 \times 10^{5}\right)$ from healthy adults. The target PMN from healthy adults were washed free of serum and fixed by the same technique noted for platelets, and the ELISA was completed as described above. Quantitation of IgG and IgM was determined from a standard curve, and the results were expressed as femtograms/PMN.

Statistical analysis. Numbers presented in tables are means $\pm \mathrm{SEM}$ for each measurement. The statistical differences $(p<$ 0.05 ) of both the direct and indirect platelet- and neutrophilassociated Ig between healthy, term neonates and the adult controls were determined by using a paired analysis of variance. 


\section{RESULTS}

Thirty-five of the 44 mothers completed the medical questionnaire. All of these mothers were in good health and not at risk for any pregnancy-related medical problems. Seven of these mothers were primigravida and 28 were multiparous. None of these mothers had any history of autoimmune diseases, gestational diabetes, hypertension, or preeclampsia. Moreover, in multiparous mothers, none cited problems with previous pregnancies including maternal or neonatal thrombocytopenia or neutropenia. Additionally, 13 of the healthy term infants in the study group were born via cesarean section and 22 by spontaneous or assisted vaginal delivery.

Platelet-associated $\operatorname{IgG}$ levels in 44 healthy neonates were markedly increased compared with adult controls: $2.52 \pm 0.36$ (mean $+\mathrm{SEM}, \mathrm{ng} / \mu \mathrm{g}$ of platelet protein) versus $0.69 \pm 0.07$ $(p<0.001)$ (Fig. 1). There were no statistical differences between the adult controls and neonates in the levels of platelet-associated $\operatorname{IgM}$ and serum bindable, platelet-associated IgG. The serum bindable IgM was significantly decreased in term neonates compared with adult controls $(p<0.001)$.

Levels of both neutrophil-associated IgG and IgM in healthy neonates were increased compared with adult controls ( $p=$ 0.039 and 0.042 , respectively) (Fig. 2). Although these measurements were statistically significant, the difference in the means of neutrophil-associated IgG and IgM between healthy, term newborns and adult controls was not as great as for platelet-associated antibodies: $642 \pm 88(\mathrm{fg} / \mathrm{PMN}$, mean \pm SEM) versus $484 \pm 34$ and $401 \pm 57$ versus $302 \pm 24$, respectively. If the normal range of adult values is considered to be the mean $\pm 2 \mathrm{SD}$ of the mean, these levels of newborn neutrophil-associated IgG and IgM fell within the upper limits of this normal range for healthy adults. Additionally, there was not a significant difference between term neonates and adult control in either serum bindable neutrophil IgG or IgM.

Of the 35 mothers who completed the questionnaire, 12 of 13 infants born by cesarean section and 20 of 22 born vaginally

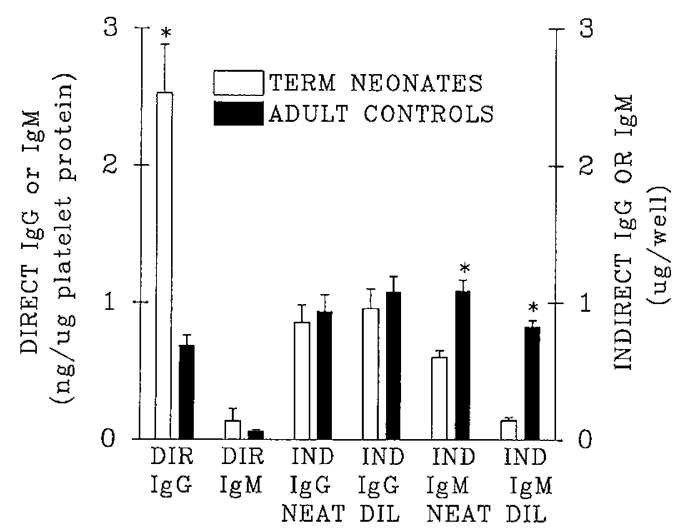

Figure 1. The amount of cell associated (direct) IgG and IgM bound to platelets is measured in nanograms $/ \mu \mathrm{g}$ of platelet protein as depicted on the left $y$ axis. The amount of serum bindable (indirect) platelet $\operatorname{IgG}$ and $\operatorname{IgM}$ measured by an ELISA with fixed, type O platelet targets is shown on the right $y$ axis. The clear bars represent the direct and indirect antibodies from healthy, term neonates, and the solid bars are identical results from healthy, adult controls. $D I R$, direct tests; IND, indirect tests; NEAT, undiluted serum; DIL, 1/20 dilution; *statistical significance between results from healthy newborns and adult controls $(p<0.05)$.

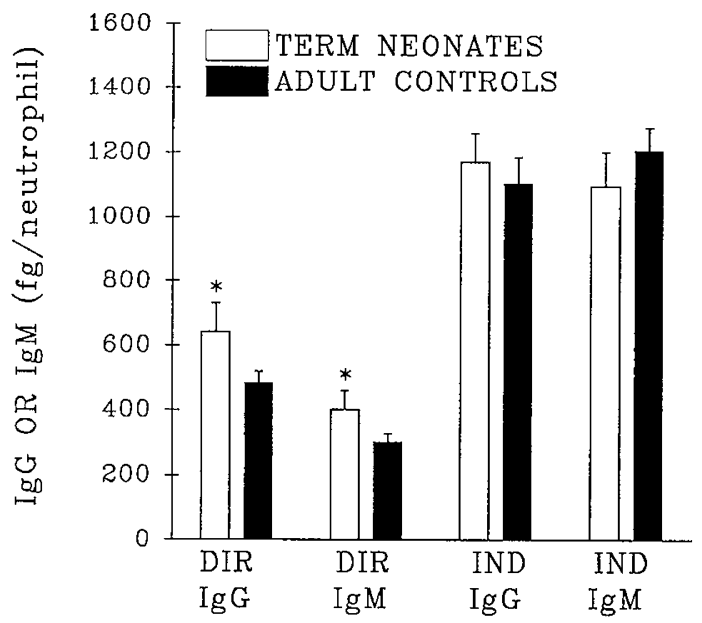

Figure 2. The amount of neutrophil-associated (direct) and serum bindable (indirect) $\operatorname{IgG}$ and $\operatorname{IgM}$ in cord samples from healthy neonates (clear bars) measured in femtograms per neutrophil compared with adult controls (solid bars). DIR, direct; IND, indirect; *statistical significance $(p<0.05)$ between results from healthy neonates and adult controls.

had increased platelet- and/or neutrophil-associated Ig. Furthermore, of the seven primigravida mothers, five infants had increased platelet- and/or neutrophil-associated Ig, whereas $26 / 28$ healthy infants of multiparous mothers had increased platelet- and neutrophil-associated Ig. Thus, there was not a significant difference in the platelet- and neutrophil-associated $\operatorname{IgG}$ or IgM with respect to the parity of the mother or to the method of delivery.

The results of the $\mathrm{CBC}$ are shown in Table 1. Thirty-five of the 44 infants had a $\mathrm{CBC}$ drawn after receiving parental consent; however, two of the specimens clotted. Thirty-three infants, $75 \%$ of the total study population, had a CBC completed. The mean absolute neutrophil count, $13156 \pm 961$ $\mathrm{PMN} / \mathrm{mm}^{3}$, at $24 \mathrm{~h}$ of age was elevated compared with the normal range, of 7 000-13 $000 \mathrm{PMN} / \mathrm{mm}^{3}$, for neonates born at 5000 feet of altitude (Table 1) $(9,10)$. One of 33 infants tested had thrombocytopenia $(104000 / \mu l)$. All of the other hematologic parameters of the study group were within the normal range for newborns at $24 \mathrm{~h}$ of age including the mean platelet volume $(10-14)$.

Initially, the study protocol allowed for the measurement of term infants only; however, due to the striking differences noted between infants and adult controls, we examined a

Table 1. Complete blood counts of healthy, term neonates at 24-36 h of age*

\begin{tabular}{lccc}
\hline \multicolumn{1}{c}{ Laboratory parameters } & $\begin{array}{c}\text { Term } \\
\text { newborns }\end{array}$ & $\begin{array}{c}\text { Healthy } \\
\text { newborn } \\
\text { controls }\end{array}$ & Reference \\
\hline Hemoglobin $(\mathrm{g} / \mathrm{dL})^{*}$ & $17.3 \pm 0.3$ & $19.3 \pm 2.2$ & 11 \\
Hematocrit $(\%)$ & $51.0 \pm 1.0$ & $61.7 \pm 4$ & 11 \\
White blood count $\left(\times 10^{-3} / \mu \mathrm{L}\right)$ & $21.4 \pm 1.0$ & $18.9(9.4-34.0)$ & 12 \\
Absolute neutrophil count $(/ \mu \mathrm{L})$ & $13156 \pm 961$ & $7000-13000$ & 10 \\
Platelet count $\left(\times 10^{-3} / \mu \mathrm{L}\right)$ & $256 \pm 14$ & $310 \pm 68$ & 13 \\
Mean platelet volume $(\mathrm{fL})$ & $8.4 \pm 1.0$ & $(7-9)$ & 1 \\
\hline
\end{tabular}

Results are expressed as the mean \pm SEM. The normal ranges are expressed as the mean $\pm \mathrm{SEM}$, the mean with ranges representing $95 \%$ confidence intervals or the range of the $95 \%$ confidence intervals alone. 
limited number of pregnant women. The levels of plateletassociated direct and indirect antibodies were measured in six pregnant, primigravida women and three pregnant, multiparous women during their third trimester. Of the six pregnant, primigravida women, one demonstrated an increase in plateletassociated $\mathrm{IgG}$, another had increased levels of both plateletassociated and serum bindable $\operatorname{IgG}$ and $\operatorname{IgM}$, and a third had increased platelet-associated $\operatorname{IgG}$ and serum bindable $\operatorname{IgM}$, compared with healthy nonpregnant controls. Additionally, of the three pregnant, multiparous women, one demonstrated increased platelet-associated and serum bindable IgG and another evidenced increased platelet-associated $\operatorname{IgG}$ and serum bindable IgM, compared with healthy, adult controls. Although the distinction between allo- and autoreactivity was not completely defined by these studies, $3 / 6$ primigravida women and 2/3 multiparous women demonstrated increased plateletassociated and/or serum bindable results.

\section{DISCUSSION}

Immune-mediated cytopenias in the newborn are predominantly the result of maternal alloimmunization to cell surface antigens that may be restricted to certain cell types or part of the HLA loci $(5,6)$. Maternal alloimmunization to HLA antigens occurs in about $40 \%$ of pregnancies; however, alloimmunization to platelet- and neutrophil-specific antigens occurs less frequently $(14,15)$. Neonatal immune-mediated thrombocytopenia has been reported to occur in $1 / 1000$ to $1 / 5,000$ live births and is due to alloimmunization to the HPA-1 locus in $80 \%$ of reported cases and to other platelet-specific alloantigens and HLA antigens in the remainder of newborns (5, 16-18). Immune-mediated thrombocytopenia also occurs in infants born to preeclamptic mothers and may account for a significant amount of thrombocytopenia in these patients $(19,20)$.

Neonatal immune-mediated neutropenia is associated with maternal alloimmunization against neutrophil specific antigens, especially NA1, NA2, NB1, and NB2, and has been reported to be as common as $1 / 500$ live births (2). In published studies, the presence of neutrophil-associated Ig was not necessarily associated with decreased neutrophil counts, for only 6 of 29 infants born to mothers alloimmunized to granulocytespecific antigens demonstrated abnormal absolute neutrophil counts (6). Autoimmune neonatal thrombocytopenia may be associated with maternal autoimmune disorders including systemic lupus erythematosus, immune thrombocytopenic purpura, hypothyroidism, lymphoproliferative disorders, or other autoimmune diseases in which IgG class autoantibodies cross the placenta and cause destruction of the infant's platelets (21-24). Neonatal neutropenia may also be associated with the passage of maternal autoantibodies across the placenta $(4,25)$. The diagnosis of autoimmune neutropenia, also known as transitory neonatal neutropenia, is dependent upon the demonstration of maternal autoantibodies directed against antigens common to both mother and fetus resulting in destruction of neutrophils (21-26).

The results from this series of healthy, term newborns have demonstrated that levels of $\mathrm{IgG}$ associated with both platelets and neutrophils were increased compared with healthy, adult controls. There was also increased amounts of neutrophilassociated IgM compared with adult controls. Although statistically different from the levels in healthy adults, these increased levels of neutrophil-associated IgG and IgM would fall within the upper limits of the normal range for healthy adults (mean $\pm 2 \mathrm{SD}$ of the mean); whereas the levels of plateletassociated $\mathrm{IgG}$ is 3 -fold that of adult controls and falls well outside the normal range. Despite the presence of these antibodies, only one infant was thrombocytopenic, and none was neutropenic. No infants in this study group had any bleeding manifestations or signs and symptoms of infection. No increase in serum bindable Ig to either neutrophils or platelets was detected; in fact, the serum bindable IgM in the serum from newborns binding to target platelets was significantly decreased with respect to adult controls. None of the abnormalities documented in this study appeared related to the parity of the mother or the method of delivery.

The presence of $\operatorname{IgM}$ on the surface of neutrophils in these healthy neonates is surprising for newborns have decreased levels of $\operatorname{IgM}$ in the serum compared with adults, $9 \mathrm{mg} / \mathrm{dL}$ (range 6-15) versus $76 \mathrm{mg} / \mathrm{dL}$ (range 37-154) (26). Maternal IgM does not cross the placenta; therefore, this IgM is probably of fetal origin. Although the fetus and term infant are able to synthesize $\operatorname{IgM}$, increased levels of $\operatorname{IgM}$ in the serum of newborn infants are thought to be predominantly due to intrauterine infections (27). The interpretation of increased IgM associated with cells is less certain. Increased levels of neutrophil-associated IgM, both direct and indirect, with concomitant neutropenia has been noted during infancy, termed autoimmune neutropenia of infancy (28). In this disorder, neutrophilspecific antigens are targets for autoantibody production (28). There is an increase in $\operatorname{IgG}$ and $\operatorname{IgM}$ or both that may result in increased levels of membrane associated Ig, serum bindable Ig, or both $(4,28)$. In comparison with the group reported here; however, these patients are neutropenic and usually older, an average age of $8 \mathrm{mo}$ (28). Moreover, in our series of neonates, the increased levels of IgM were statistically greater but may be considered in the normal range when compared with healthy adult controls (mean $\pm 2 \mathrm{SD}$ ) (Fig. 2). Although the clinical relevance of this neutrophil-associated $\operatorname{IgM}$ is unknown, it is important to document this increase for proper interpretation of measurements of neutrophil-associated $\mathrm{Ig}$ in neonates.

An interesting feature of this study relates to absolute neutrophil counts. The infants in our study exhibited increased absolute neutrophil counts similar to that documented by Carballo et al. (9) and Manro et al. (10) who demonstrated increased neutrophil counts in healthy, term infants born at 5000 feet of altitude compared with infants at or below 500 feet. The reason for this finding is not clear, but its existence has been demonstrated.

The results of our studies with platelets and neutrophils from term infants was unexpected. Preliminary evaluation of samples from primiparous and multiparous women unrelated to the newborn study group was completed to define whether the higher levels of platelet-associated $\operatorname{IgG}$ in term neonates may be due to increased levels of platelet-associated Ig in the mother during the third trimester of pregnancy. Over half of the women tested had positive cell-associated or serum bindable 
assays; thus, the increased amounts of direct platelet associated IgG may be of maternal origin. The nature of the immunoreactivity and its implications for turnover and function of platelets and neutrophils during the third trimester of pregnancy and in the newborn are undefined and beyond the scope of this study. However, the mean platelet volume of platelets from cord blood was within the normal range for age possibly indicating that there was not increased turnover of these cells. Further investigations are needed to expand and evaluate these observations including measurement of these Ig during the first year of life as well as documenting the source of the Ig, its specificity, and possible clinical implications. In addition, because there is no published data on the binding characteristics of platelets and neutrophils from cord blood in comparison to mature platelets and neutrophils, it would be important to ensure that no differences in binding characteristics between these cells exist. An increased propensity for nonspecific Ig binding on the surface of cells may have clinical implications. Mature neutrophils which are coated with Ig, autoantibodies in these cases, are reported to have a defect in chemotaxis (29). Neonatal neutrophils also have a deficit in chemotaxis but other differences are known to exist in comparison to mature neutrophils including decreased numbers of CD11b/CD18 receptors, deficits in f-actin polymerization, decreased numbers of specific granules as well as others $(7,30,31)$. Therefore, a possible etiology for the observed chemotactic defect of neonatal neutrophils may be secondary to the presence of Ig on their surface; however, further study is required to delineate the chemotactic defects observed in neonatal neutrophils. Nevertheless, it is clear that neutrophils and platelets from newborn infants have increased amounts of $\mathrm{Ig}$ associated with them. This fact should be taken into account for the proper interpretation of measurements of cell-associated Ig completed on cells from the newborn and compared with results of samples from healthy adults.

\section{REFERENCES}

1. Castle V, Andrew M, Kelton J, Giron D, Johnston M, Carter C 1986 Frequency and mechanism of neonatal thrombocytopenia. J Pediatr 108:749-755

2. Levine DH, Madyastha PR 1986 Isoimmune neonatal neutropenia. Am J Perinatol 3:231-233

3. Castle V, Coates G, Kelton JG, Andrew M $1987{ }^{111}$ In-oxine platelet survivals in thrombocytopenic infants. Blood 70:652-656

4. Madyastha PR, Glassman AB 1989 Neutrophil antigens and antibodies in the diagnosis of immune neutropenias. Ann Clin Lab Sci 19:146-154

5. Reznikoff-Etievant MF 1988 Management of alloimmune neonatal and antenatal thrombocytopenia. Vox Sang 55:193-201
6. Skacel PO, Stacey TE, Tidmarsh CEF, Contreras M 1989 Maternal alloimmunization to HLA, platelet and granulocyte-specific antigens during pregnancy: its influence on cord blood granulocyte and platelet counts. Br J Haematol 71:119-123

7. Ambruso DR, Brentwood B, Henson PM, Johnston RB Jr 1984 Oxidative metabolism of cord blood neutrophils: relationship to content and degranulation of cytoplasmic granules. Pediatr Res 18:1148-1153

8. Markwell MAK, Haas SM, Bieber LL, Tolbert NE 1978 A modification of the Lowry procedure to simplify protein determination in membrane and lipoprotein samples. Anal Biochem 87:206-210

9. Carballo C, Foucar K, Swanson P, Papile LA, Watterberg KL 1993 Effect of high altitude on neutrophil counts in newborn infants. J Pediatr 119:464 -466

10. Manro B, Browne R, Weinberg AG, Rosenfeld CR 1976 Normal leukocyte (WBC) values in neonates. Pediatr Res 10:428

11. Zaizov R, Matoth Y 1976 Red cell values on the first postnatal day during the last 16 wk of gestation. Am J Hematol 1:275-278

12. Dallman PR 1977 White blood cells: developmental changes in the newborn. In Rudolph AM (ed) Pediatrics. Appleton-Century-Crofts, New York, pp 1088 -1089

13. Hathaway WE 1975 The bleeding newborn. Semin Hematol 12:175-188

14. Terasaki PI, Mickey MR, Yamasaki JN, Vredevoe D 1970 Maternal foetal incompatibility. I. Incidence of HLA antibodies and possible association with congenital abnormalities. Transplantation 9:538-543

15. Lalezari P, Nussbaum M, Gelman S, Spaet T 1960 Neonatal neutropenia due to maternal isoimmunization. Blood 15:236-243

16. Pearson HA, Shulman NR, Marder VJ, Cone TE 1964 Isoimmune neonatal purpura: clinical and therapeutic considerations. Blood 23:154-177

17. Mueller-Eckhardt C, Kiefel V, Grubert A, Kroll H, Weisheit M, Schmidt S, MuellerEckhardt G, Santoso S 1989348 cases of suspected neonatal alloimmune thrombocytopenia. Lancet 1:363--366

18. Blanchette VS 1988 Neonatal alloimmune thrombocytopenia: a clinical perspective. Curr Stud Hematol Blood Transfus 54:112-126

19. Samuels P, Main EK, Tomaski A, Mennuti MT, Gabbe SG, Cines DB 1987 Abnormalities in platelet antiglobulin tests in preeclamptic mothers and their neonates. Am J Obstet Gynecol 157:109-113

20. Burrows RF, Hunter DJS, Andrew M, Kelton JG 1987 A prospective study investigating the mechanism of thrombocytopenia in preeclampsia. Obstet Gynecol 70:334338

21. Karpatkin S, Strick N, Karpatkin MB, Siskind GW 1972 Cumulative experience in the detection of antiplatelet antibody in 234 patients with idiopathic thrombocytopenic purpura, systemic lupus erythematosus, and other clinical disorders. Am J Med 52:776-785

22. Nathan DJ, Snapper I 1958 Simultaneous placental transfer of factors responsible for LE cell formation and thrombocytopenia. Am J Med 25:647-653

23. Seip M 1960 Systemic lupus erythematosus in pregnancy with hemolytic anemia, leucopenia, and thrombocytopenia in the mother and her newborn infant. Arch Dis Child 35:364-366

24. de Swiet M 1985 Maternal autoimmune disease and the fetus. Arch Dis Child 60:794-797

25. van Leeuwen EF, Roord JJ, de Gast GC, Vander Plas-van Dalen C 1983 Neonatal neutropenia due to maternal autoantibodies against neutrophils. BMJ 287:94

26. Buckley RH, Dees SC, O'Fallon WB 1968 Serum immunoglobulins. I. Levels in normal children and uncomplicated allergy. Pediatrics 41:600-611

27. Wara DW, Ammann AJ 1982 Immunologic Disorders. In: Rudolph AM and Hoffman JIE (eds) Pediatrics. Appleton-Century-Crofts, New York pp 407-409

28. Lalezari P, Khorshidi M, Petrosova M 1986 Autoimmune neutropenia of infancy. J Pediatr 109:764-769

29. Goddard DH, Kirk AP, Kirwan JR, Johnson GD, Holborrow EJ 1984 Impaired polymorphonuclear leucocyte chemotaxis in rheumatoid arthritis. Ann Rheum Dis 43:151-156

30. Miller ME 1971 Chemotactic function in the human neonate: humoral and cellular aspects. Pediatr Res 5:487-491

31. Anderson DC, Rothlein R, Marlin SD, Krater SS, Smith CW 1990 Impaired transendothelial migration by neonatal neutrophils: abnormalities of Mac-1 (CD11b/CD18) dependent adherence reactions. Blood 78:2613-2621

32. Hilmo A, Howard T $1987 \mathrm{~F}$-actin content of neonatal and adult neutrophils. Blood 69:945-949 